\title{
The Activation of Learners' Metacognition to Promote Learning Autonomy of Good Language Learners
}

\author{
Aam Ali Rahman ${ }^{1 *}$, Anggi Angraeni ${ }^{1}$, Rizal Ahmad Fauzi ${ }^{1}$ \\ ${ }^{1}$ Universitas Pendidikan Indonesia
}

\begin{abstract}
During the COVID-19 pandemic, the mode of teaching and learning shifted from mostly offline into the online process. In online learning, interaction and engagement are limited. Thus, it is urgent to prepare students to become autonomous. The activation of students' metacognition is one aspect assumed to be crucial in their learning autonomy. So, this research aimed to describe the relationship between the learning autonomy of good language learners and the activation of their metacognition. This article employed a case study of qualitative design. Thirty participants categorized as autonomous language learners were chosen purposively. They are categorized as autonomous good language learners since they meet the five criteria of autonomous learners by Holec (1981). The data were analyzed through contextual coding. The result shows that $92 \%$ of the participant has activated their metacognition. Meanwhile, $8 \%$ of participants become autonomous learners without activating their metacognition. This $8 \%$ of participants fulfill two of them: orchestrating learning strategies and evaluating learning. Thus, it can be assumed that the activation of metacognition relates to the learning autonomy implemented by good language learners. However, it is not a decisive factor. It needs further study to analyze other learner intrinsic behaviors that probably influence the learning autonomy of good language learners, such as learners' anxiety, motivation, and self-esteem.
\end{abstract}

Keywords: Metacognition; Learning Autonomy; Language learning

\section{INTRODUCTION}

Previously, the teaching and learning process took place at school, where students and teachers interacted through various teaching and learning techniques. Since the Covid19 pandemic hit, the education field has also got an impact. Academic interaction has been limited. Many schools have been closed for a particular time. Flipped learning in the flipped classroom comes to use as a solution since students and teachers cannot hold the teaching/learning process faceto-face. The flipped classroom is a pedagogical method using asynchronous video to replace the teachers' explanation, practice problems as homework, and vigorous group-based problem-solving activities in the classroom. It represents a unique combination of learning theories once thought incompatible (Bishop \& Verleger, 2013).

The challenge of this situation is the limited teacher-student engagement compared to regular learning. The initial stage of flipped learning can even lead to student frustration and less satisfaction (Fisher et al., 2017). Many researchers employed various methods in applying technology to flipped learning, from the simplest one about lexical learning (Rahman \& Angraeni, 2020) to writing (Luo et al., 2020), even by providing material using a mobile phone (Andujar et al., 2020). Fostering which, it is essential to prepare the students, to some extent, with the capacity of learning autonomy.

Some experts defined learning autonomy from psychological, methodological, and content dimensions. From a psychological perspective, it is one of the detachment capacities, critical reflection, decision making, and independent action (Little et al., 2017). From a methodological perspective, since pedagogy has been acknowledged as the method in education, autonomy is viewed as learners' ability to take charge of their learning. It includes all decision-making regarding the learning they wish to involve (Holec, 1979). The third dimension of learning autonomy is the content. From this perspective, language learners are expected to decide how and when they learn and what and where they learn. It adds up to the social and political philosophy of learning autonomy (Benson, 2013).

Nevertheless, it is believed that to become autonomous, learners should enhance their metacognition. It should involve a repeated diagnosis of learners' beliefs about language learning, preferred styles, learning needs, and objectives to equip them with criteria for choosing optimum strategies, resources, and activities for their individualized programs (Victori \& Lockhart, 1995).

Metacognition is defined as thinking about thinking (Anderson, 2002). It is the ability to reflect on what is known

Corresponding Author e-mail: alirahman@upi.edu https://orcid.org/0000-0001-8683-1400

How to cite this article: Aam Ali Rahman $1{ }^{*}$, Anggi Angraeni2, Rizal Ahmad Fauzi3 (2021). The Activation of Learners' Metacognition to Promote Learning Autonomy of Good Language Learners. Pegem Journal of Education and Instruction, Vol. 11, No. 4, 2021, 248-253

Source of support: Nil

Conflict of interest: None.

DOI: $10.47750 /$ pegegog.11.04.24

Received: 10.06.2021

Accepted: 21.08.2021 Publication: 01.10.2021 
and involve thinking back on an event, describing what happened and its feelings. Metacognition results in critical but healthy reflection and evaluation of thinking that may make specific changes in how learning is managed and in the strategies chosen for this purpose (Griffiths, 2008).

Learning autonomy and metacognition are two of the variables of good language learners. These two variables share similarities in criteria. The criteria of learning autonomy are: determining learning objectives, defining the contents and progression of learning, selecting methods and techniques to be used, monitoring the procedures of acquisition, and evaluating what has been acquired (Holec, 1979). The criteria of learning metacognition are: preparing and planning for learning, selecting, and using strategies, monitoring learning, orchestrating strategies, and evaluating learning (Griffiths, 2015a).

It is assumed that identifying and analyzing good language learners' characteristics and learning strategies is essential for language teachers. The results and information gained from the process can be used by teachers to determine aspects of teaching. However, good language learners' lessons can only effectively be used if teachers apply explicit and implicit instructional techniques in their programs. These techniques cover how teachers raise awareness, practices, and evaluation (Griffiths, 2015b).

Good language learners' common characteristics are: "being highly-motivated, being active, personalizing their learning, differentiating language registers and styles, being self-reflective, and being keen to go native" (Le Ho, 2011).

The usage of different strategies is also claimed to distinguish between good and poor language learners. The differences lie in the range and the cognitive level of the learning strategies used. Good language learners tend to use a more excellent range of strategies. They also select strategies that involve a higher degree of metacognitive awareness (Kayaoglu, 2013). Good language learners consider the learning context, learning goal, and individual characteristics in choosing effective learning strategies. Learning from that lesson, teachers should also pay attention to those aspects(Griffiths, 2015b).

Thus, it is interesting to find out about the relationship between those variables of good language learners. This study aimed to describe the relationship between the learning autonomy of good language learners and the activation of their metacognition.

\section{Method}

\section{Participants}

Twenty-six students of graduated program majors in the English Education Department took part in this research. They were chosen using purposive random sampling from the population: Graduated Program of English Education Department. However, 12 out of 20 students were employed as participants. They were taken because they were considered autonomous learners from the result of the questionnaire analysis. All 12 participants were given a survey to identify their learning metacognition.

\section{Data Collection}

From the population, 26 participants were randomly taken. They were tested using an online-based form developed from learning autonomy criteria to check whether they were autonomous or non-autonomous learners. They were tested using a self-developed questionnaire. The result of the questionnaire showed that only 12 participants were categorized as autonomous learners.

Further, the 12 autonomous learners were filled in the survey to check their metacognitive level. They were asked to answer five open-ended questions through online-based forms without any treatments: Did you usually plan before learning? What aspect(s) of learning that you think need more preparation? Please explain; Do you think you have the ability to select and apply your learning strategies? What factor(s) that you consider in the selection?; Do you continuously monitor your learning? Which one do you think is more important to monitor, the learning procedures or the skill acquisition? Please elaborate; Can you apply the learning strategies you have chosen well? How effective do you think those strategies are?; and, Do you find learning evaluation necessary? How and to what aspect(s) is usually the scope of your learning evaluation?

After collecting the survey data, the participants' answers were analyzed using contextual coding (Bell, 2014; Birmingham \& Wilkinson, 2003; Greaney et al., 2012; Hamied, 2017; Silverman, 2013; Walliman, 2005), categorized as the following: preparing and planning for learning, selecting and using strategies, monitoring learning, orchestrating strategies, and evaluating learning (Griffiths, 2008). The result of coding was the source to decide which aspect of metacognition appears on participants.

\section{Data Analysis}

Descriptive qualitative analysis was employed to answer the research question for this study (Silverman, 2013). The researcher played as a complete observer without interfering with participants' answer choices. Five open-ended questions were given to the participants. Each of which represents aspects of learning metacognition. The answer to those five open-ended questions was analyzed and categorized. From the categorized data, the result of the metacognitive aspect can be seen clearly. The complete result of data analysis is discussed in the finding and discussion. Finally, complete content and organizational editing before formatting. 


\section{FINDINGS AND DISCUSSION}

Analysis of the questionnaire shows that 12 out of 26 participants met all the criteria of autonomous language learners. The 26 participants are recognized as good language learners. By analyzing the questionnaire, it is found that 12 of them own all the criteria of learning autonomy. The criteria of autonomous learning behavior involve "the responsibility for (1) determining learning objectives, (2) defining the contents and progression of learning, (3) selecting methods and techniques to be used, (4) monitoring the procedures of acquisition, and (5) evaluating what has been acquired" (Holec, 1979). Thus, it is assumed that the 12 participants later be termed as autonomous good language learners. The rest 14 participants missed one or two out of five criteria. So, they are categorized into non-autonomous good language learners.

The 12 autonomous good language learners were involved in a survey to identify to which extent their components of metacognition have been activated. The criteria of learning metacognition chosen for the identification are: "(1) preparing and planning for learning, (2) selecting and using strategies, (3) monitoring learning, (4) orchestrating strategies, and (4) evaluating learning" (Griffiths, 2008).

Generally, data shows that 11 participants apply all the components of metacognition. There is only one participant that applies partially. However, there is a variation on level and tendencies among those who entirely apply the principles of learning metacognition. To be precise, each component is discussed as follow:

\section{Preparing and Planning for Learning}

Eleven participants stated that they prepare and plan for their learning, and one participant does not. Nevertheless, the 11 participants apply the process to different degrees of frequency. Five participants stated that they always prepare and plan their learning. Six other participants sometimes apply the process only in particular conditions. Whereas one participant seldom applies the process. They cannot explain the reason or in what condition they would do the process. They responded to the question regarding the process of preparing and planning for learning with a statement such as, "I will do if I want to do." So, it can be argued that there is a possibility that motivation plays a role. Since they cannot identify the reason for doing or not doing the process, the motivation may be intrinsic. Intrinsic motivations do not require external rewards but expressions of ones' sense of who one is, of what interests them (Deci \& Ryan, 2010).

Besides, there is also variation in the objects of preparation. Some participants focus on the learning strategy. Some others focus on material preparation. Nevertheless, the rest of them focus on how to monitor the process through scheduling. However, in all objects that they prepared, they tend to consider the objectives of their learning. It explains the relation between the components of metacognition and the concept of learning autonomy. Since they all are autonomous learners, determining objectives is a capacity they have internalized, including their metacognition behaviors.

As the implication of this discussion to teaching autonomy, it is significant to ensure that teachers/lecturers encourage them to determine their learning objectives and utilize them to prepare and plan for learning.

\section{Selecting and Using Learning Strategies}

The context of this metacognition component indicates that the learners can analyze and decide how to execute their learning process (Anderson, 2002). It covers the selection of learning methods and techniques, which is a criterion of learning autonomy. The data shows that 11 out of 12 participants usually select and use learning strategies. They stated they believe they have enough learning experiences and understand their characteristics to decide what learning strategy best works to attain their learning objectives. They claimed that they know their strengths and weaknesses. This assumption is in line with the theory of good language learners. Good language learners reflect on the learning context, the learning goal, and characteristics (Griffiths, 2015b).

Still, there are only one of the participants dares to assure the effectiveness of their selection. Most of them thought that the characteristics of materials should also be measured in choosing strategy. It adds up the dimension of the learning context. In that sense, they assumed that they still need guidance from lecturers/instructors to decide their learning strategy. They need to be led to understand the learning context. We can assume that the capacity of learning autonomy in this stance is not absolute autonomy since lecturers' scaffolding is still generally needed. In other words, the lecturer must facilitate their students to become strategic through particular teaching strategies.

\section{Monitoring Learning Strategy Use}

The concept of learning autonomy and learning metacognition share their criteria on this aspect. However, the monitoring procedure of acquisition (a criterion of learning autonomy) and the monitoring of learning strategy (a component of learning metacognition) are different in tools and targets. If the monitoring procedure of acquisition (learning method) uses a set of actions, the monitoring learning strategy can use more than one procedure. Besides, the learning strategy aims for a more general target than the learning procedure of acquisition. In other words, a learning strategy may consist of one or more procedures.

The data displays those 11 participants monitor their learning strategy, and two participants do not. Those who do not apply the process reasoned that they never did it 
consciously, but they might have to monitor their learning strategy subconsciously through self-reflection and selfassessment. That is why they can identify what kind of learning fits them well. So, possibly, it is not that they do not monitor, but they somewhat did not know what learning strategy is (Boström \& Lassen, 2006).

Four participants replied that they usually reflect on the learning strategy, and six habitually reflect on their acquisition procedures. Learning from this fact, lecturers need to lead the students to self-reflection while conducting a particular learning method or strategy. It can provide students with experience by monitoring their learning strategy, whether they have to adapt, change specific procedures/actions, or even change the strategy when needed.

\section{Orchestrating strategies}

Eleven participants responded that they could orchestrate learning strategies. One participant did not make sure if he/she orchestrated a learning strategy. They assumed the implementation of the strategy they have selected did not always work well. Some intrinsic factors are aroused to respond to the question of "what factors are important to assure the success of your learning strategy implementation?'. Those are self-commitment, courage, creativity, critical thinking. At the same time, the factor that weakens the implementation of students' learning strategy is lecturers' teaching policy.

As discussed earlier, good language learners tend to use various learning strategies. They also tend to choose metacognitive strategies (Kayaoglu, 2013). They also displayed distinctly better abilities to plan for thinking and revise their task approach after identifying problems. It urges the importance of metacognitive knowledge as a supporting factor in effective metacognitive teaching.

The implication is that teachers and lecturers, using critical thinking, should help students establish the habit of self-checking their understanding and task approach. Related metacognitive knowledge should also be communicated explicitly when necessary (Ku \& Ho, 2010). This habit of selfchecking contributes to one criterion of learning autonomy, defining the content and progress of learning.

\section{Evaluating Learning}

This component also shares an idea with the concept of learning autonomy. The difference lies in the focus when learning metacognition focuses on evaluating learning as a process; learning autonomy focuses on evaluating what has been acquired by the process (the result).

The result of data analysis demonstrates that all participants usually evaluate their learning. They believe that by evaluating both the process and the result of learning, they will develop resolutions of what should and should not be done to improve the following learning. They can also improve the result of their learning, both the behavioral changes and the score.

The aspect of the process of learning covers the strategy and monitoring it. The aspect of learning results covers the objectives and their attainability. This finding to the teaching instruction implies that teachers/lecturers can stimulate students to do a comprehensive evaluation by giving leading questions such as (1) What am I trying to accomplish? (2) What strategies am I using? (3) How well am I using them? (4) What else could I do? (Anderson, 2002).

After elaborating on the components of learning metacognition, it can be assumed that implications can be learned to improve the quality of teaching instructions. Learning metacognition is the capacity of learning to learn. Teachers'/lecturers' teaching strategy is essential to activate this capacity. They can interfere by stimulating, facilitating, giving experiences, or giving options in pre, post-learning processes.

The activation of this learning metacognition also contributes to learning autonomy and taking charge of learners' learning. From the perspective of constructivism, since both concepts promote learner-centeredness, the activation of these two learner variables and other learner variables and learning variables is adequate to accomplish learners' success in learning (Wang, 2011).

\section{CONCLUSION}

Learning autonomy as one of the learner variables in pedagogy contributes to learners' success in learning. In the English language learning context, the activation of this variable may lead them to be good language learners. Holec (1979) stated that learning autonomy could be defined as learners taking charge of their learning.

However, there is a debate on whether learning autonomy contributes to good language learners or only good language learners who can implement learning autonomy. It is believed that to be able to demonstrate learning autonomy. The learners need to activate the capacity, namely learning metacognition, to learn how to learn (Victori \& Lockhart, 1995). In short, to foster excellent learning achievement, learners need to make themselves autonomous learners and to become autonomous learners, metacognition is required. Thus, this study means to unravel the relation between those two variables, Learning autonomy, and learning metacognition.

The five components of metacognition: Preparing and Planning for Learning; Selecting and Using Learning Strategies; Monitoring Learning Strategy Use; Orchestrating strategies; Evaluating Learning were questioned to elaborate by the autonomous good language learners. From the analysis of the responses to the survey, it can be assumed that there is a pattern between the two variables. Those who are autonomous learners are, to some extent, can also be categorized as learners 
with metacognition. This tendency can be explained from a constructivist perspective where the concept of learnercentered influences both variables.

However, it cannot be denied that some autonomous learners come out without showing all metacognitive criteria, as it is proven in this research: one out of twelve participants of this research is considered as the autonomous learner without showing all five mentioned components. More comprehensive research on other learner variables related to the anomaly circumstance is needed.

\section{SUGGESTION}

As an implication of this study, teachers/lecturers need to be aware of these two variables and develop a teaching strategy that pays attention to them to assure a higher degree of success in language teaching and learning. Precisely in this circumstance where flipped learning is considered as a solution to respond to the Covid-19 pandemic. In this situation, engagement is lessened. So, the students need to somehow own the capacity of learning autonomy by activating learning metacognition.

\section{References}

Anderson, N. J. (2002). The Role of Metacognition in Second Language Teaching and Learning. ERIC Digest.

Andujar, A., Salaberri-Ramiro, M. S., \& Martínez, M. S. C. (2020). Integrating Flipped Foreign Language Learning through Mobile Devices: Technology Acceptance and Flipped Learning Experience. Sustainability, 12(3). https://doi.org/10.3390/ $\underline{\text { su12031110 }}$

Bell, J. (2014). Doing Your Research Project: A guide for first-time researchers. McGraw-Hill Education (UK).

Benson, P. (2013). Teaching and researching: Autonomy in language learning. Routledge.

Birmingham, P., \& Wilkinson, D. (2003). Using research instruments: A guide for researchers. Routledge.

Bishop, J. L., \& Verleger, M. A. (2013). The flipped classroom: A survey of the research. ASEE national conference proceedings, Atlanta, GA,

Boström, L., \& Lassen, L. M. (2006). Unraveling learning, learning styles, learning strategies and meta-cognition. Education + Training, 48(2/3), 178-189. https://doi. org/10.1108/00400910610651809

Deci, E. L., \& Ryan, R. M. (2010). Intrinsic Motivation. In The Corsini Encyclopedia of Psychology (pp. 1-2). https://doi.org/https://doi. org/10.1002/9780470479216.corpsy0467
Fisher, R., Ross, B., LaFerriere, R., \& Maritz, A. (2017). Flipped learning, flipped satisfaction, getting the balance right. Teaching \&amp; Learning Inquiry, 5(2), 114-127. https://doi. org/10.20343/teachlearninqu.5.2.9

Greaney, A.-M., Sheehy, A., Heffernan, C., Murphy, J., Mhaolrúnaigh, S. N., Heffernan, E., \& Brown, G. (2012). Research ethics application: A guide for the novice researcher. British Journal of Nursing, 21(1), 38-43.

Griffiths, C. (2008). Lessons from good language learners (C. Griffiths, Ed.). Cambridge University Press.

Griffiths, C. (2015a). Language learning strategies: An holistic view. Studies in second language learning and teaching(3), 473-493.

Griffiths, C. (2015b). What have we learnt from 'good language learners'? ELT Journal, 69(4), 425-433. https://doi.org/10.1093/ elt/ccr040

Hamied, F. A. (2017). Research Methods: A Guide for First-Time Researchers. UPI Press.

Holec, H. (1979). Autonomy and foreign language learning. ERIC.

Holec, H. (1981). Learner autonomy and language learning. Council of Europe, 1981, 66-74.

Kayaoglu, M. N. (2013). Poor and Good Learners' Language Beliefs and Their Influence on Their Language Learning Strategy Use. Novitas-ROYAL (Research on Youth and Language), 7(1), 36-54.

Ku, K. Y. L., \& Ho, I. T. (2010). Metacognitive strategies that enhance critical thinking. Metacognition and Learning, 5(3), 251-267. https://doi.org/10.1007/s11409-010-9060-6

Le Ho, G. A. (2011). Understanding good language learners of Vietnamese as a foreign language. Electronic Journal of Foreign Language Teaching, 8(2), 385-398.

Little, D., Dam, L., \& Legenhausen, L. (2017). Language learner autonomy: what, why and how. Second Language Acquisition.

Luo, Z., O’Steen, B., \& Brown, C. (2020). Flipped learning wheel (FLW): a framework and process design for flipped L2 writing classes. Smart Learning Environments, 7(1). https://doi. org/10.1186/s40561-020-00121-y

Rahman, A. A., \& Angraeni, A. (2020). Empowering Learners with Role-Playing Game for Vocabulary Mastery. International Journal of Learning, Teaching and Educational Research, 19(1). https://doi.org/10.26803/ijlter.19.1.4

Silverman, D. (2013). Doing qualitative research: A practical handbook. Sage.

Victori, M., \& Lockhart, W. (1995). Enhancing metacognition in selfdirected language learning. System, 23(2), 223-234. https://doi. org/https://doi.org/10.1016/0346-251X(95)00010-H

Walliman, N. (2005). Your research project: a step-by-step guide for the first-time researcher. Sage.

Wang, P. (2011). Constructivism and learner autonomy in foreign language teaching and learning: To what extent does theory inform practice. Theory and Practice in Language Studies, 1(3), 273-277. 